\title{
The Status and Pronounced Effect of Multicultural Education: The Case of Madda Walabu University Ethiopia
}

\author{
Awol Ahmed Mohammed \\ Department of Educational Planning and Management, College of Education and Behavioral Studies, Madda Walabu \\ University, Bale Robe, Ethiopia \\ Email: awol.ahamed@yahoo.com
}

How to cite this paper: Mohammed, A.A. (2020) The Status and Pronounced Effect of Multicultural Education: The Case of Madda Walabu University Ethiopia. Open Access Library Journal, 7: e6250. https://doi.org/10.4236/oalib.1106250

Received: March 22, 2020

Accepted: April 19, 2020

Published: April 22, 2020

Copyright $\odot 2020$ by author(s) and Open Access Library Inc.

This work is licensed under the Creative Commons Attribution International License (CC BY 4.0).

http://creativecommons.org/licenses/by/4.0/ (c) (i) Open Access

\begin{abstract}
The purpose of the study is to investigate the status and pronounced effect of multicultural education at Madda Walabu University, Ethiopia. Recently Madda Walabu University and the other universities of Ethiopia are becoming the center of ethnic conflicts. Most of the students and teachers have lower awareness of the concept of multicultural education. Pertinent paradigms such as positivism and interpretivism were entertained. The mixed-method research design was used. In this study questionnaire was gathered from 146 (Male 129 and Female 17) of the university teachers. In-depth interview and focus group discussion were used to collect information from 6 administrative workers and 12 students respectively. The result of the study indicates that there is little practice of multicultural activity in the university. Most of the students and teachers have lower awareness of the concept of multicultural education. The contents are not integrated with the issue of multiculturalism. The curriculum should be integrated with multicultural issues. Moreover the curriculum is not sufficiently favored with the experiences of gender equality. The university has not arranged facilities and means to enable the disabled students. The university should design strategy to increase multicultural education issues and gender experiences.
\end{abstract}

\section{Subject Areas}

Education

\section{Keywords}

Multiculturalism, Multicultural Education, Status, Challenges, Pronounced Effects 


\section{Introduction}

Culture is a collaboration of shared meanings or common beliefs among an organization's members. It is an integral to the learning process. It is the organization and way of life with in the community of students and teachers and directs the way they communicate, interact and approach teaching and learning [1]. Culture is a complex process which includes knowledge, belief, art, morals law, custom and others. It is a system of values and norms that are shared among a group of people and that when taken together constitute a design for living. It is software of mind [2]. According to him the main elements of culture are attributed as value, attitudes, belief and norms. Value as a bed rock of culture is a view of what is desirable. It includes attitudes towards individual freedom, democracy, truth, justice, honesty, loyalty and local obligation.

Culture is a total set of symbols by which the adherents of a given society identify one another, at the same time differentiate them from other people not belonging to a particular society [3]. Culture tells or indicates who we are, rather where we belong. It conveys the blue print that controls a person's whole being, fillings, thinking and behavior. Moreover it is the way we interrelate with people. Culture influences our own knowledge, beliefs and values [4].

There are two viewpoints of multicultural education mainly concerning the view of many scholars in the Globe, namely the "Assimilation or 'melting-pot' perspective" of MCE (Multi Cultural Education) and the "Pluralism" or the "Global Perspective" [5].

The assimilation perspective mainly stresses that micro cultures must give up their original culture and identifies in order to blend in or become absorbed in the predominant culture. On the other hand the Global or Pluralism Perspective is that micro cultures can retain many of the traditions such as language, religion and social customs while adapting many of the aspects of the predominant culture. The global perspective recognizes Cultural Pluralism as an ideal and healthy state in any productive society and promotes equity and respect among the existing cultural groups [6]. One can officially infer from this that global or pluralism is the true and real view which clearly reflects justice, honesty and loyalty.

Multicultural education is the development of citizens for a more democratic society through provision of more accurate and comprehensive disciplinary knowledge and through enforcement of students' academic achievement and critical thinking applied to social problems. Moreover this is strengthened with the promotion of the values of diversity and equal opportunity for all people through understanding of the contributions and perspectives of people of different races, ethnicities, cultures, languages, religions, genders, sexual orientations, physical abilities and disabilities [7] [8]. It is a social change through education. It is another aspect of the continuous human journey towards justice and the fulfillment of the premises of democracy. 
Multicultural refers to the consideration and appreciation of diversity of cultures as distinctive to and enriching for global humanity and social order [9] Moreover multiculturalism or multicultural policy remains a comparatively new concept that suggests the presence of numerous different cultures living together. It is an approach in following commitment, understanding and cultural discussion among cultures, so that various cultures can peacefully co-exist with less tension. Although there is a general support on the general issues of multiculturalism, there are also inner conflicts on the plans and social cohesion of its implementation.

[10] states the benefit of multicultural education like the following:

- Multicultural education increases positive relationships through achievement of common goals, respect, appreciation and commitment.

- Multicultural education decreases stereotyping and prejudice through direct oriented and interactions among diverse individuals.

- Multicultural education renews vitality of society through the richness of different cultures of its members and fosters development of a broader and more sophisticated view of the world.

The government of Higher Education Institutes should be pavilions of diversity, where students come from different religion, cultural, ethnic, language and economic groups. The institutions should be constructive in establishing the rights of all students regardless of their religion, ethnic, language, social and political outlooks. Whenever students and teachers with different cultural and ethnic come together there can be certain opportunities and challenges.

As diversity increases in higher education students, teachers and other workers should be more critical, alert, and knowledgeable to face the challenges that may occur. According to scholars like [11] and [12] diverse working groups are more productive than homogeneous groups. Students would be culturally rich if they are taught by culturally different teachers. Diversity may bring us great values and richness of life and can also create better understanding of our own personal culture. In some of the higher education institutions politicizing diversity is becoming one of the issue and phenomena. In Ethiopia recently higher education institutes are becoming centers of the challenges of diversity and ethnic conflicts. There is less effort done by the university under study to solve the conflict issues. The Ethiopian universities must do a lot to raise the level of awareness of the community. One of the opportunities of diversity in the higher education could be that a student can be exposed to the cultures other than their own cultural issue.

[13] states that, the government should support the basis of equality, the growth and enrichments of the various cultures and enrichment of cultures and traditions that are compatible with fundamental rights and democratic norms. In line with this, [14] states that the education should promote democratic culture, tolerance and peaceful resolutions of differences which are based on the sense of responsibility. 
In a country like Ethiopia, where there is cultural diversity, the nature of education should be multicultural in all of its characters. The curriculum, the syllabus and the textbooks should be designed and processed from the perspective of diverse cultural background. The curriculum should be designed to fulfill the needs of different ethnic groups.

The researcher believes that the practice of multicultural education at Madda Walabu University and other Ethiopian universities should be applicable because of the following reasons:

- To promote equality, tolerance, peaceful coexistence and mutual understanding among the communities of higher educations.

- To adjust and actualize certain mechanism that could able to minimize the conflict occurring.

- To establish certain mechanism that students come from different social groups should be able to act and live together based on mutual respect and tolerance by democratically raising the awareness of the students and other workgroups in the universities.

- To empower minority groups, females, the disabled and others to be able to communicate with the other social groups on the basis of equality and democratic outlook.

- To clearly work the curriculum that could bring democratic culture and sustainability.

Many students come to universities at a critical stage of their development. It is a time during which they define themselves in relation to others and exercise different social roles before making permanent commitment to occupations. Whenever people with different social groups, ethnic, language, religion and culture come together for the educational purpose there are certain challenges and opportunities [15].

Currently the universities in Ethiopia are becoming the centers of ethnic conflicts. Students from different cultural groups are fighting continuously for less than a decade. There is one study by [16] that was made with the issue of multicultural education in Ethiopian universities. The study did not address the problem clearly and efficiently. Moreover no study conducted on multi-cultural education which is pertinent to Madda Walabu University. Because of this and the other reasons stated above, the researcher is convinced and motivated to study the status and pronounced effects of multi-cultural study in this university. Moreover the topic is of paramount importance for the following reasons:

- To reduce ethnic conflicts in the universities.

- The result of the study can create multi-cultural education awareness of the students and the teachers.

- It can raise the capability of the students towards the better achievement of the quality of the education.

- It can build interaction between diverse cultures.

- Create tolerance between different ethnic and cultural groups in the universi- 
ties.

The main purpose of this study is to explore the status and pronounced effect of multicultural education at Madda Walabu University; specifically the following main research questions are investigated.

$>$ To what extent does Madda Walabu University practice multi-cultural education?

What are the challenges of multi-cultural education in the university?

What are the strategic solutions to minimize the challenges that are occurring in the university?

\section{Research Design and Methods}

The paradigm of this study is mainly based on the integration of positivism and interpretivism. The methodological approach of the study is ethnography which is based on the exploration of cultural groups. Descriptive survey was used as a quantitative research design where phenomenology is qualitative. The descriptive is used to obtain information concerning the current status of the phenomena and to describe what exists with respect to variables or conditions in a situation [17]. Hence the descriptive survey was used to portray the status and pronounced effect of multicultural education at Madda Walabu University.

Moreover the survey was used to select a representative sample from the entire population and to administer the questionnaire in order to describe the attitudes, opinions, behaviors [18]. In this study the mixed research design (both quantitative and qualitative) was used to actualize the data. To substantiate the data in-depth interview and focus group discussion was conducted accordingly.

The design of questionnaire will depend on whether the researcher wishes to collect qualitative information or quantitative information. A well designed questionnaire should meet research objectives, should obtain most accurate information and should make it easy for respondents to give the necessary information. Some of the basic principles for designing good questionnaire are the organization of the questionnaire flow, that the questions are better to be short and simple and double barreled questions should be avoided [19].

According to [20] the principles of effective questionnaire design include, to decide the information required and to put the questionnaire into an appropriate sequence. Pre-testing the layout of the questions, revising and finalizing to administer the questions are the final attributes. The researcher has taken into account those stated designs and principles to collect the questionnaire from 146 of the university teachers. The questions were based on a 5 item Likert scale. A Likert scale is a psychometric scale commonly involved in research used to represent people's opinions and attributes to a topic or subject matter. 5 point Likert scale consists of 5 answer options which will contain 2 extreme poles and neutral options connected with intermediate answer options. This scale is easier for respondents to understand, is ideal for a larger study and is helpful to produce better distribution of data [21]. The researcher has adopted this 5 Likert 
scale technique to collect the questionnaire from the respondents. In this study questionnaire were gathered from 146 Madda Walabu University teachers (male 129 and female 17).

In-depth interview was used to collect information from 6 administrative personnel and focus group discussion was made with 12 students from different parts of 6 colleges.

\subsection{Target Population and the Sample of the Study}

A population consists of all the subjects you want to study, since it is usually not possible to reach all the members of the target population, one must identify that portion of the population which is accessible [22]. Side by side sampling is the process of selecting group of subjects for a study in such a way that individuals represent the large group from which they are selected. This representation of portion of a population is called a sample [23]. The target population consisted of 9 colleges that are found in Madda Walabu University. Out of this, 6 colleges are taken randomly as an accessible population. The 6 colleges are Engineering, Computing, Natural Science, Business and Economics, Social Science and Education and Behavioral Science. The total number of teachers in colleges is 440 ( 389 males and 51 females). Out of this $33 \%$ is taken as random sampling for questionnaire which becomes 146 (129 males and 17 females). Besides, semi-structured interview was made to collect information from the purposely selected 6 administrative officials. According to [24] time and resources may not allow conducting a large number of semi-structured interviews, it is important to get the perspectives of more than just a few people, such as key administrators and program board members. Semi-structured interviews allow the respondents to express their own view with freedom and can provide reliable, comparable qualitative data [25]. In respect of this the 6 administrative officials are taken from 4 different academic colleges, each of which has direct relation with the daily activities of the teachers, 1 administrative expert from Vice President Academic Office and 1 expert from the university student affairs office.

A focus group discussion involves gathering people from similar backgrounds or experiences together to discuss a specific topic of interest. It is a form of qualitative research where questions are asked about their perceptions, attitudes, beliefs, opinions or ideas. It encourages discussion with the participants. It involves similar groups usually 6 to 8 or 8 to 12 . It is based on developing key questions, developing agenda and planning how to record the result [26].

Taking into account the guide principles and procedures, the researcher has invited 2 suitable participant students from each of the 6 sampled academic colleges and in general these 12 students were purposely selected for the data sampling. Careful wording of the key questions was recorded and any observation during the session was sorted out and included in the report. In this respect focus group discussion was made with 12 students purposely selected from the sampled 6 colleges. 


\subsection{Data Gathering Instruments}

The questionnaire developed were based on a 5 item Likert scale, which is adjusted as 1 = definitely disagree to 5 definitely agree. Closed ended questions were used to get response from the 146 subjects. Similarly interview was collected from the 6 interviewees and the 12 students appeared for focus group discussion. Pilot study was made with 8 lecturers. It can assist the researcher in determining the flaws of limitations or other weaknesses within the design of the instruments. To check the stability and consistency reliability was determined with the 8 lecturers through Cronbach's Alpha. The sample questions were administered to the lecturers in the 2 colleges of the university that are not included in the main study. The validity of the instrument refers to the extent to which the instrument measures what is intended to measure [27]. Based on this the researcher submitted the questions to higher experts for ensuring the validity of the measuring instruments. In line with this, the pilot analyses of item total correlation below 0.25 and above 0.8 were eliminated.

\subsection{Methods of Data Analysis}

In this study, for the analysis of the quantitative data, the SPSS version 20 was used to calculate the frequency, percentage, mean, standard deviation, chi-square and t-test. The SPSS was used because it is quick to administer and suitable for the type of the data obtained. Qualitative data were organized into themes and narrated to substantiate the quantitative results.

\section{Results and Discussion}

The data gathered through questionnaire. Interview and FGD (focus group discussion) is presented in the following tables and analysis.

\subsection{The Status of Multi-Cultural Education in Madda Walabu University}

$\mathrm{DD}=$ Definitely disagree $=1 \mathrm{DS}=$ Disagree somewhat $=2 \mathrm{UD}=$ Undecided $=3$ $\mathrm{AS}=$ Agree somewhat $=4 \mathrm{DA}=$ Definitely agree $=5$

In this study 1 and 2 are taken as (disagree) and 4 and 5 are taken as (agree).

As can be seen from the table the overall average Pearson chi-square is 5.050 is by far greater than the critical value $(1,0.05)$ which is 3.84 . The overall average $p$. value 0.402 is greater than the conventionally accepted significance differences level of $0.05(0.05 \mathrm{P}>0.05)$. This indicates there is no statistically significant difference between the values. This clearly emphasizes that there is no association between the sex of the respondents and the status of multi-cultural education or there is no statistical relationship. Officially the chi-square statistic used in the test of independence is labeled Pearson Chi-square. This statistic can be evaluated by comparing the actual value against a critical value found in a chi-square distribution. The result from Table 1 item No 1 indicates that Pearson chi-square is 4.09 which is still greater than the critical value $(1,0.05)=3.84$. 
Table 1. Chi Square Test for the status.

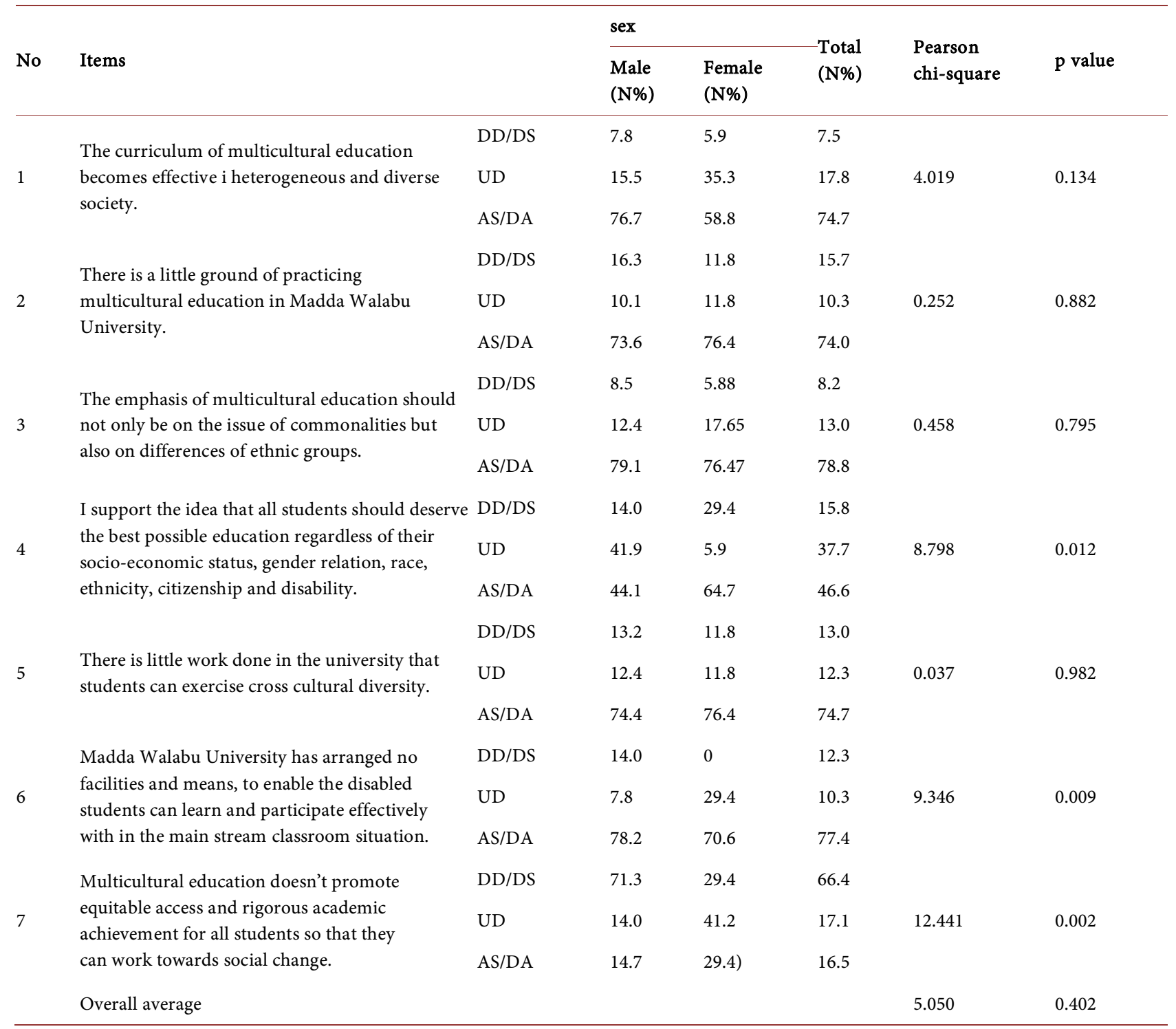

The overall result of $\mathrm{x}^{2}$ is greater than critical value $(1,0.05)$ which is 3.84 , the pre-determined alpha level of significance is $(0.05)$ and degree of freedom $(\mathrm{df})$ is 1 . Total respondents are 146 (Male 129 and Female 17).

From Table 1 item 1, the result from the teachers shows that the majority of the teachers (74.7) agree somewhat or definitely agree that the curriculum of multicultural education becomes effective in heterogeneous and diverse society. Similarly as can be seen from Table 1 item No 2, the majority of the teachers (74\%) agree that there is little ground of practicing multi-cultural education at Madda Walabu University. Furthermore as it is shown in item No 3 and item No 4 respectively, the majority of the teachers $(78.8 \%)$ and (46.6\%) have an idea that the emphasis of multicultural education should not only be the issue of commonalities but also be the issue of differences of ethnic groups and that all students should deserve the best possible education regardless of their differences of social categories. 
The calculated Pearson chi-square for Table 1 No 5 is 0.037 which is less than the critical value $(1.0 .05)=3.84$. The result from the teachers clearly depicts that there is little work done in the University for the Students to exercise cultural activity. Table 1 No 6 reveals that the university has not arranged facilities and means to enable the disabled students can learn and participate effectively within the main stream classroom situation. Table 1 item No 7 shows that the majority of the teachers (66.4) reject the idea that multicultural education does not promote equitable access and rigorous academic achievement. The chi square result (12.441) indicates that there is no statistically significant difference between the values. The overall average of the calculated Pearson chi-square for the whole items in the table is 5.050, which indicates that there is little practice or exercise of multicultural education at Madda Walabu University.

Interviews were conducted with 4 administrative employees or workers as a means of qualitative data. The data achieved from the 4 interviewees revealed:

- There is little practice of multi-cultural education at Madda Walabu University.

- So far no prepared guideline prepared in the university that could be able to reflect diversity issues.

- There are few attempts of gender trainings and not adequate to increase the awareness issues.

- The university has not arranged the necessary facilities for the disabled students and the reason is due to the problems with the design of the classrooms, libraries, roads and other in fractural installations.

- There are fewer attempts exercised in the university with the local community.

- There are fewer reflections of diversity issues in the substances of the curriculum. The contents are not integrated with the experiences of multicultural education.

Furthermore the interviewees indicated that the university under study and also the other universities in Ethiopia are becoming centers of ethnic conflicts and other political issues. The issues and the cases for the conflicts are easily triggering the emotions of the students. The conflicts were manifested in forming different groups mainly based on the basis of identity. The data obtained during the FGD (Focus Group Discussion) from 10 students is in line or agrees with the result of interview data stated above. Moreover the students attentively stressed that there is little exercise done in the university to raise the awareness of the students coming from various cultural backgrounds. The students pointed out clearly that there are little practices in the curriculum of the university reflecting multi-cultural issues.

\subsection{Sample T-Test for the Status of Multi-Cultural Education at the University}

T-test was used to identify the status of multicultural education in Madda Wa- 
labu University. The t-test was employed to determine whether there are significant differences between the sex of the respondents and the status of multicultural education. The data achieved clearly elucidate that there is no association between the sex of the respondents and the contents in the table. The t-test is identified in the content of the table to show whether the sample mean is higher or lower than the expected mean value.

As it is shown in Table 2 the result of the sample t-test of the teachers revealed that the grand mean of score of teachers (2.4334) is significantly higher than the expected mean value (2) at $\mathrm{t}=7.953, \mathrm{df}=145, \mathrm{p}<0.05$. This result indicates that there is little ground of practicing multi-cultural education in the university and there is lack of facilities to enable the disabled students can participate in the main stream of classroom situation. It is the idea and the agreement of the majority of the teachers that multi-cultural education promotes equitable access and rigorous academic achievement.

Table 2. Sample t-test.

\section{One-Sample Test}

\section{Test Value $=2$ \\ Test Value $=2$}

No Items

The curriculum of multicultural education

1 becomes effective i heterogeneous and diverse society.

\begin{tabular}{|c|c|c|c|c|c|c|c|c|}
\hline \multirow[t]{2}{*}{ No } & \multirow[t]{2}{*}{ Items } & \multirow[t]{2}{*}{$\mathrm{t}$} & \multirow[t]{2}{*}{$\mathrm{df}$} & \multirow{2}{*}{$\begin{array}{l}\text { Sig. } \\
\text { (2-tailed) }\end{array}$} & \multirow[t]{2}{*}{ Mean } & \multirow{2}{*}{$\begin{array}{l}\text { Std. } \\
\text { Deviation }\end{array}$} & \multicolumn{2}{|c|}{ of the Difference } \\
\hline & & & & & & & Lower & Upper \\
\hline 1 & $\begin{array}{l}\text { The curriculum of multicultural education } \\
\text { becomes effective i heterogeneous and diverse } \\
\text { society. }\end{array}$ & 13.263 & 145 & 0.000 & 2.6712 & 0.61149 & 0.5712 & 0.7713 \\
\hline 2 & $\begin{array}{l}\text { There is a little ground of practicing } \\
\text { multicultural education in Madda Walabu } \\
\text { University. }\end{array}$ & 9.382 & 145 & 0.000 & 2.5822 & 0.74978 & 0.4595 & 0.7048 \\
\hline 3 & $\begin{array}{l}\text { The emphasis of multicultural education } \\
\text { should not only be on the issue of } \\
\text { commonalities but also on differences of } \\
\text { ethnic groups. }\end{array}$ & 13.925 & 145 & 0.000 & 2.7055 & 0.61215 & 0.6053 & 0.8056 \\
\hline 4 & $\begin{array}{l}\text { I support the idea that all students should deserve } \\
\text { the best possible education regardless of their } \\
\text { socio-economic status, gender relation, race, } \\
\text { ethnicity, citizenship and disability. }\end{array}$ & 5.106 & 145 & 0.000 & 2.3082 & 0.72934 & 0.1889 & 0.4275 \\
\hline 5 & $\begin{array}{l}\text { There is little work done in the university that } \\
\text { students can exercise cross cultural diversity. }\end{array}$ & 10.532 & 145 & 0.000 & 2.6164 & 0.70721 & 0.5008 & 0.7321 \\
\hline 6 & $\begin{array}{l}\text { Madda Walabu University has arranged no } \\
\text { facilities and means, to enable the disabled } \\
\text { students can learn and participate effectively } \\
\text { with in the mainstream classroom situation. }\end{array}$ & 11.382 & 145 & 0.000 & 2.6507 & 0.69075 & 0.5377 & 0.7637 \\
\hline 7 & $\begin{array}{l}\text { Multicultural education doesn't promote } \\
\text { equitable access and rigorous academic } \\
\text { achievement for all students so that they can } \\
\text { work towards social change. }\end{array}$ & -7.914 & 145 & 0.000 & 1.5000 & 0.76339 & -0.6249 & -0.3751 \\
\hline & Grand mean score of Teachers & 7.953 & 145 & 0.00 & 2.4334 & 0.69487 & 0.4983 & 0.6543 \\
\hline
\end{tabular}

$<2$ = Disagree, 2 = Undecided, $>2=$ Agree . 


\subsection{The Challenge of Multicultural Education in Madda Walabu University}

$\mathrm{DD}=$ Definitely disagree $=1 \mathrm{DS}=$ Disagree somewhat $=2 \mathrm{UD}=$ Undecided $=3$

AS $=$ Agree somewhat $=4 \mathrm{DA}=$ Definitely agree $=5$

In this study 1 and 2 are taken as (disagree) and 4 and 5 are taken as (agree).

As can be seen from Table 3 the overall Pearson chi square 10.524 is by far greater than the critical value $(1,0.05)$ which is 3.84 . The overall average $\mathrm{p}$. Value 0.238 is greater than the conventionally accepted significance level of 0.05 that is $(p>0.05)$ indicating there is no association between the values or no association between the sex of the respondents and the implementation of multi-cultural education. Table 3 item No 1 indicates that the Pearson chi-square 15.857 is by far greater than the critical value $(1,0.05)=3.84$. The respondents for item No 1 are in dilemma, not sure whether the university has prepared or not directive guideline of multi-cultural education. The result indicates (50\%) of the teachers have replied these prepared guidelines whereas (34.9) replied that there is no prepared guideline. However the interview held with the administrative workers confirmed that there is no directive guideline in the university to foster positive multiculturalism interactions and understandings. As shown in Table 3 item No 2, the chi square 26.633 is by far greater than the critical value $(1,0.05)$ which is 3.84 . The item indicates, the majority of the teachers $(55.5 \%)$ don't support the idea that the contents are not favored with the experiences of multicultural education. Hence a lot to be done to revise the curriculum. As shown in Table 3, item 3 the majority of the teachers (81.5\%) confirmed that there is little done in the university to arrange trainings of multiculturalism.

From Table 3 item No 5 the majority of the teachers (81.5\%) confirmed that the students in the university have lower awareness to the concept of multi-cultural education. Similarly (82.3\%) of the teachers under Table 3 Item No 6 confirmed that the disabled students are not getting equivalence learning opportunities as that of the abled students. Table 3 item No 7 indicates that the majority of the teachers $(52.7 \%)$ confirmed that the courses given in the university are not integrated with the issues of gender equality and gender experiences. The calculated $X^{2} 19.273$ is greater than the standard value $(1,0.05)=3.84$. From this one can infer that there are lots of works expected to be done with the issue of gender cases.

The date achieved from the interviewees indicates that there is no adequate strategy designed in the university to minimize the issue of ethnic and other conflicts. The university is not working with full potential to manage diversity and conflicts. The result of the interview shows that it seems lots of conflicts and problems are backed with socially and politically aggravated issues. According to the interviewee the curriculum prepared is not designed considering the relevance and equivalence of the curriculum. Moreover the result from the interview shows there is no multi-cultural training that was conducted in the university. Moreover there is no strong bond between the university and the surrounding 
community. Similarly the data obtained from the FGD (Focus Group Discussion) with 10 students confirms all the idea that is given by the interviewee.

As shown in Table 4 the result of the t-test of the teachers revealed that the grand mean score of teachers 2.2827 is significantly higher than the expected mean value (2) at $\mathrm{t}-=5.678, \mathrm{df}=145, \mathrm{p}<0.05$. The result indicates that there is no directive guideline in the university to foster positive multicultural interactions and understandings. There is little done to conduct training of multiculturalism. Moreover the result indicates that the students have lower awareness of multicultural education and the courses are not integrated with the experiences of gender equality and experiences.

Table 3. Chi Square test for the challenge of Multicultural Education (MCE).

\begin{tabular}{|c|c|c|c|c|c|c|c|}
\hline \multirow[b]{2}{*}{ No } & \multirow[b]{2}{*}{ Items } & & \multicolumn{2}{|l|}{$\operatorname{sex}$} & \multirow[b]{2}{*}{$\begin{array}{l}\text { Total } \\
(\mathrm{N} \%)\end{array}$} & \multirow[b]{2}{*}{$\begin{array}{l}\text { Pearson } \\
\text { Chi-square }\end{array}$} & \multirow[b]{2}{*}{$p$ value } \\
\hline & & & $\begin{array}{l}\text { Male } \\
(\mathrm{N} \%)\end{array}$ & $\begin{array}{l}\text { Female } \\
(\mathrm{N} \%)\end{array}$ & & & \\
\hline \multirow{3}{*}{1} & \multirow{3}{*}{$\begin{array}{l}\text { Madda Walabu University has not prepared } \\
\text { proper and directive guidelines that can } \\
\text { enhance proper awareness of multicultural } \\
\text { education. }\end{array}$} & $\mathrm{DD} / \mathrm{DS}$ & 55.8 & 15.9 & 50.0 & \multirow{3}{*}{15.857} & \multirow{3}{*}{0.000} \\
\hline & & UD & 12.4 & 35.3 & 15.1 & & \\
\hline & & AS/DA & 31.8 & 58.8 & 34.9 & & \\
\hline \multirow{3}{*}{2} & \multirow{3}{*}{$\begin{array}{l}\text { The contents that I teach in the courses do } \\
\text { not encourage the better achievement of } \\
\text { multicultural education. }\end{array}$} & $\mathrm{DD} / \mathrm{DS}$ & 62.8 & 0.0 & 55.5 & \multirow{3}{*}{26.633} & \multirow{3}{*}{0.000} \\
\hline & & UD & 14.7 & 23.5 & 15.8 & & \\
\hline & & AS/DA & 22.5 & 76.5 & 28.7 & & \\
\hline \multirow{3}{*}{3} & \multirow{3}{*}{$\begin{array}{l}\text { Madda Walabu University has failed to } \\
\text { arrange trainings of multicultural education. }\end{array}$} & $\mathrm{DD} / \mathrm{DS}$ & 10.9 & 5.9 & 10.3 & \multirow{3}{*}{0.657} & \multirow{3}{*}{0.720} \\
\hline & & UD & 17.8 & 11.8 & 8.2 & & \\
\hline & & AS/DA & 81.3 & 82.3 & 81.5 & & \\
\hline \multirow{3}{*}{4} & \multirow{3}{*}{$\begin{array}{l}\text { There is no proper directive guideline that } \\
\text { is helpful for the gender trainings. }\end{array}$} & $\mathrm{DD} / \mathrm{DS}$ & 16.3 & 0.0 & 14.4 & \multirow{3}{*}{7.79} & \multirow{3}{*}{0.020} \\
\hline & & UD & 16.3 & 41.2 & 19.2 & & \\
\hline & & AS/DA & 67.4 & 58.8 & 66.4 & & \\
\hline \multirow{3}{*}{5} & \multirow{3}{*}{$\begin{array}{l}\text { The students in Madda Walabu University } \\
\text { have lower awareness towards the concept } \\
\text { of multicultural education. }\end{array}$} & $\mathrm{DD} / \mathrm{DS}$ & 9.3 & 0.0 & 8.2 & \multirow{3}{*}{2.601} & \multirow{3}{*}{0.272} \\
\hline & & UD & 9.3 & 17.6 & 10.3 & & \\
\hline & & AS/DA & 81.4 & 82.4 & 81.5 & & \\
\hline \multirow{3}{*}{6} & \multirow{3}{*}{$\begin{array}{l}\text { In the University the disabled students are } \\
\text { not getting equivalence learning } \\
\text { opportunities in the program with all of } \\
\text { the rest non-disabled students. }\end{array}$} & $\mathrm{DD} / \mathrm{DS}$ & 12.4 & 5.9 & 11.6 & \multirow{3}{*}{0.855} & \multirow{3}{*}{0.652} \\
\hline & & UD & 7.8 & 11.8 & 8.2 & & \\
\hline & & AS/DA & 79.8 & 82.3 & 80.2 & & \\
\hline \multirow{3}{*}{7} & \multirow{3}{*}{$\begin{array}{l}\text { The courses I'm teaching are with luck of } \\
\text { the issues of gender equality and gender } \\
\text { experience. }\end{array}$} & $\mathrm{DD} / \mathrm{DS}$ & 58.1 & 11.8 & 52.7 & \multirow{3}{*}{19.273} & \\
\hline & & UD & 20.2 & 17.6 & 19.9 & & 0.000 \\
\hline & & AS/DA & 21.7 & 70.6 & 27.4 & & \\
\hline Ove & ll average & & & & & 10.524 & 0.238 \\
\hline
\end{tabular}

Most of the items are greater than $\mathrm{X}^{2}$ critical value $(1,0.05)$ which is 3.84 , the pre-determined alpha level of significance $(0.05)$ and degree of freedom $(\mathrm{df})$ is 1. The total for male respondents is 146 . (Male 129 and Female 17). 
Table 4. The result of $\mathrm{t}$-test for the challenge of multiculturalism at the university.

\begin{tabular}{|c|c|c|c|c|c|c|c|c|}
\hline \multicolumn{9}{|c|}{ One-Sample Test } \\
\hline \multirow{3}{*}{ No } & \multirow{3}{*}{ Items } & \multicolumn{7}{|c|}{ Test Value $=2$} \\
\hline & & \multirow[t]{2}{*}{$\mathbf{t}$} & \multirow[t]{2}{*}{$\mathrm{df}$} & \multirow{2}{*}{$\begin{array}{l}\text { Sig. } \\
\text { (2-tailed) }\end{array}$} & \multirow[t]{2}{*}{ Mean } & \multirow[t]{2}{*}{ SD } & \multicolumn{2}{|c|}{$\begin{array}{l}95 \% \text { Confidence Interval } \\
\text { of the Difference }\end{array}$} \\
\hline & & & & & & & Lower & Upper \\
\hline 1 & $\begin{array}{l}\text { Madda Walabu University has not prepared } \\
\text { proper and directive guidelines that can } \\
\text { enhance proper awareness of multicultural } \\
\text { education. }\end{array}$ & -1.996 & 145 & 0.048 & 1.8493 & 0.91231 & -0.2999 & -0.0015 \\
\hline 2 & $\begin{array}{l}\text { The contents that I teach in the courses do } \\
\text { not encourage the better achievement of } \\
\text { multicultural education. }\end{array}$ & -3.663 & 145 & 0.000 & 1.7329 & 0.88115 & -0.4113 & -0.1230 \\
\hline 3 & $\begin{array}{l}\text { Madda Walabu University has failed to arrange } \\
\text { trainings of multicultural education. }\end{array}$ & 13.389 & 145 & 0.000 & 2.7123 & 0.64283 & 0.6072 & 0.8175 \\
\hline 4 & $\begin{array}{l}\text { There is no proper directive guideline that is } \\
\text { helpful for the gender trainings. }\end{array}$ & 8.552 & 145 & 0.000 & 2.5205 & 0.73550 & 0.4002 & $0 . .6409$ \\
\hline 5 & $\begin{array}{l}\text { The students at Madda Walabu University } \\
\text { have lower awareness towards the concept of } \\
\text { multicultural education. }\end{array}$ & 14.705 & 145 & 0.000 & 2.7329 & 0.60219 & 0.6344 & 0.8314 \\
\hline 6 & $\begin{array}{l}\text { In the University the disabled students are not } \\
\text { getting equivalence learning opportunities in } \\
\text { the program with all of the rest non-disabled } \\
\text { students. }\end{array}$ & 12.313 & 145 & 0.000 & 2.6849 & 0.67214 & 0.5750 & 0.7949 \\
\hline 7 & $\begin{array}{l}\text { The courses I'm teaching are with luck of the } \\
\text { issues of gender equality and gender experience }\end{array}$ & $e^{-3.554}$ & 145 & 0.001 & 1.7466 & 0.86153 & -0.3943 & -0.1125 \\
\hline & Grand Mean score of teachers & 5.678 & 145 & 0.007 & 2.2827 & 0.7582 & 0.2762 & 0.4070 \\
\hline
\end{tabular}

$<2$ = Disagree, $2=$ Undecided, $>2=$ Agree.

\section{Discussion}

The focus of this study is the investigation of the status and pronounced effect of multicultural education at Madda Walabu University. It is the agreement of the majority of the teachers that multicultural education promotes equitable access and rigorous academic achievement. All students should deserve the best possible education regardless of their differences of social categories. This approach coincides with the study by [28] Banks and Banks (2010) that students should be adopted with multicultural education mentality and be provided with the school environment having equality of opportunities regardless of their social categories. Individuals will naturally be successful in an education in which they find themselves in all senses.

At Madda Walabu University there is little work done for the students to exercise multicultural activity. The majority of the teachers confirmed that most of the students and teachers have lower awareness to the concept of multicultural education and there are less or no organized multicultural trainings so far designed. In line with this the studies by [29] state most of pre service teachers have lower awareness to teach different minority groups.

The result of the study reveals, there are less reflections of diverse issues in the 
substance of the curriculum. The contents are not favored with the experiences of multicultural education. Hence, revising the curriculum would be of paramount importance. Effective and balanced multi-cultural education increases productivity and overcomes prejudice. It develops interpersonal communication, cultural awareness and prevents social conflicts.

According to [30] [31] institutions of higher educations should be integrated with the issues of contents of diversity. The increased diversity in the curriculum of higher institutions can benefit students from all backgrounds. Increasing learning environments that are supportive of diversity can lead to more openness to diversity, critical thinking skills and greater personal development. The courses given at Madda Walabu University are not integrated with the issues of gender equality and gender experience. There are few attempts of gender trainings. The university is not working in its fullest capacity to manage diversity and conflict issues occurring in the university. There are occasional reflections of ethnic conflicts. The university has not arranged facilities and means to enable the disabled students.

\section{Conclusions}

At Madda Walabu University there is little work done for the students to exercise multicultural activity. The result revealed that the majority of the students and teachers have lower awareness of the concept of multicultural education. More training is important because of the nature of the diversity of the classrooms.

The contents are not integrated with the experiences of multicultural education. The implementation of diversity workshops in universities can help in creating common understanding and appreciation of diversity. It is possible to raise and enhance the level of awareness of teachers, students and administrative workers in the university by establishing cultural centers and clubs with minimum cost requirements. Students benefit more from diverse instructors and possibly lose the benefits when diversity decreases.

\section{Recommendation}

Based on the findings and the discussion the following issues are recommended:

- Adequate and long trainings of multicultural education should be given to the teachers and the students. Tutorial classes, guidance and counseling centers and establishment of cultural clubs are expected to be encouraged by the university.

- The curriculum and the syllabi should be revised by the concerned bodies in the Ministry of Education of the country and the teachers in the university. It is important to include cross cultural issues.

- The higher education institutes in Ethiopia should work together across multi-cultural issues. Relevant guideline which is based on appropriate models of multicultural education should be developed.

- The university should strive to create awareness among its stake holders and 
the community to exercise diversity models and principles to every aspect of the university activities. Well-developed gender trainings should be developed and exercised for all of the university communities.

- Classrooms and departments should be reconstructed in such a way to sustain cultural responsive methodology and that students can practice the value of different cultures.

\section{Acknowledgements}

Above all I would like to thank Allah (God), the Sovereign, the Great for the guidance in the work of this article. I would like to express my gratitude to all those who gave their time and assistance to the completion of this article.

\section{Limitation of the Study}

The limitation of the study is those characteristics of design or methodology that impacted or influenced the application or interpretations of the result of the study [32]. The major limitations are:

- The empirical study is confined to one university. This could limit the generalizability of the findings to all universities in the country-Ethiopia. Therefore the researcher feels the study lucks comprehensiveness in scope.

- The study is the first of its kind in the university under study. A literature is hardly found on the issue. This clearly puts an impact on the study.

- The data is collected from teachers, few students and administrators excluding the concerned bodies in the ministry of education and the surrounding community officials. This may have limited the depth of the information obtained. Collecting data from the latter stakeholders could have given a more complete picture of the title of the study.

\section{Suggestions for Further Research}

Although the study has attained its anticipated objectives, it has opened up avenues for further research in the following areas:

- It would be useful to replicate this study, using larger samples, chosen to represent not only the teachers but also most of the students.

The present study suggests that there is much to be explained as regard to awareness, diversity and curriculum revision, as they relate to multi-cultural education which a further study can probe into.

A comparative study should be taken across the Ethiopian Universities whether or not there are differences among the universities as regards the implementation of multicultural education.

Further investigation of the multicultural issue pertinent to the local context should be assessed and developed.

\section{Conflicts of Interest}

I here declare the status and promising effect of multicultural education in 
Madda Walabu University is my original work and that all the sources that I used have been indicated and acknowledged by means of complete references. The author is with full responsibility that could be raised and conflict of interest of ownership, ethical and financial issues.

\section{References}

[1] Collbert, P.J. (2010) Developing a Culturally Responding of Faculty Students and Institutions, Johnson and Wales University USA. Comparative Issue in Education Research, 3, 9. https://doi.org/10.19030/cier.v3i9.231

[2] Hofstede, G. (2000) Culture Consequences. International Differences in Work Related Value. Sage, London.

[3] UNESCO (2009) Trends in Global Higher Education.

[4] Gollnick, D.M. and Chinn, P.C. (2002) Multicultural Education in Pluralistic Society. 6th Edition, Pearson Education Inc., Upper Saddle River, NJ.

[5] Clark, C. and Gorski, P. (2000) Multicultural Education and Digital Divide: Focus on Socioeconomic Class Background. Multicultural Perspectives, 4, 25-36. https://doi.org/10.1207/S15327892MCP0403_6

[6] Wiles, J. and Brondi, J.B. (2002) Curriculum Development. A Guide to Practice. 6th Edition, Pearson Education, Upper Saddle River, NJ.

[7] Kitano, M. (1998) Multicultural Curriculum Transformation in Higher Education. Allen and Bacon, New York.

[8] Aydin, H. (2013) A Literature Based Approaches on Multicultural Education, Curriculum and Instruction Department. Yildoz Technical University, Istanbul, Turkey.

[9] Hellstem, M. (2007) Multiculturalism (Major Entry). In: Anderson, M.G.L. and Herr, K., Eds., Encyclopedia of Activism and Social Justice, Springer, Berlin.

[10] Gollnick, D.M. and Chinn, P.C. (2011) Multicultural Education in Pluralistic Society. 9th Edition, International Edition, Pearson, Boston, MA.

[11] Maruyama, G. and Moreno, F. (2000) University Faculty Views about the Value of Diversity on Campus and in the Classroom. ACE, Washington DC.

[12] Wardle, F. (1998) Global Management Report. Education for All. The World on Track. UNESCO, Paris.

[13] Federal Democratic Republic of Ethiopia (1995) Proclamation No. 1/1995 of the Constitution of FDRE. Addis Ababa, Ethiopia.

[14] Transitional Government of Ethiopia (1994) New Education and Training Policy. EMPDA, Addis Ababa.

[15] Yirga, A. and Bejitual, T. (2007) Higher Education Institutions as Pavilions of Diversity: Opportunities and Challenges: The Case of Bahirdar University. The Ethiopian Journal of Education, 4, 49-68.

[16] Enyew, C. and Melesse, S. (2018) The Integration of Multiculturalism into the Ethiopian Universities. Environment, Research in Pedagogy, 8, 52-62. https://doi.org/10.17810/2015.70

[17] Descriptive Research (2008) Research Design for Social Science Work and the Human Services. Columbia University Press, New York.

[18] Creswell, J.W. (2009) Research Design: Qualitative, Quantitative and Mixed Methods Approaches. SAGE Publications, London. 
[19] Crawford, I.M. (1990) Marketing Research Centre for Agricultural Marketing Training in Eastern and Southern Africa, Harare, Zimbabwe.

[20] Sadman, S. and Bradburn, N.M. (1973) Asking Questions. 208-228.

[21] Jamison, S. (2004) Likert Scales. How to (AB) Use Them. Medical Education, 38, 1217-1218. https://doi.org/10.1111/j.1365-2929.2004.02012.x

[22] Lichtman, M. (2010) Qualitative Research in Education: A User's Guide. 2nd Edition, SAGE Publication Inc., Thousand Oaks, CA.

[23] Kothari, C.R. (2004) Research Methodology. Methods and Techniques. New Age International Ltd., New Delhi.

[24] Galletta, A.M. (2013) Mastering the Semi Structured Interview and Beyond. NYU Press, New York. https://doi.org/10.18574/nyu/9780814732939.001.0001

[25] Warren, C.A.B. and Karner, T.X. (2005) Discovering Qualitative Methods: Field Research Interviews and Analysis. Roxbury Publishing Company, Los Angeles, CA.

[26] Morgan, D.L. (1988) Focus Group as Qualitative Research. Sage, London, UK.

[27] Gray, D.E. (2004) Doing Research in the Real World. Age Publication, New Delhi.

[28] Banks, J. and Banks, C. (2004) Handbook of Research on Multicultural Education. Jossey-Bass, San Francisco, CA.

[29] Martines, D. (2005) Teachers Perceptions of Multicultural Issues in School Settings. The Qualitative Report, 10, 1-20.

[30] Castenada, C.R. (2004) Teaching and Learning in Diverse Class Rooms. Routledge Falmer, New York.

[31] Hu, S. and Kuh, G. (2003) Diversity Experiences and College Students Learning and Personal Development. Journal of College Student Development, 44, 320-334. https://doi.org/10.1353/csd.2003.0026

[32] Gray, L.R. (1992) Educational Research Competencies for Analysis and Application. 5th Edition, MacMillan Publishing Company, Orlando, FL. 